\title{
Glycine Inhibitory Dysfunction Induces a Selectively Dynamic, Morphine-Resistant, and Neurokinin 1 Receptor- Independent Mechanical Allodynia
}

\author{
Loïs S. Miraucourt, Xavier Moisset, Radhouane Dallel, and Daniel L. Voisin \\ INSERM, U929, F-63000 Clermont-Ferrand, France, Université Auvergne-Clermont1, F-63000 Clermont-Ferrand, France, and Centre Hospitalier \\ Universitaire Clermont-Ferrand, F-63000 Clermont-Ferrand, France
}

\begin{abstract}
Dynamic mechanical allodynia is a widespread and intractable symptom of neuropathic pain for which there is a lack of effective therapy. We recently provided a novel perspective on the mechanisms of this symptom by showing that a simple switch in trigeminal glycine synaptic inhibition can turn touch into pain by unmasking innocuous input to superficial dorsal horn nociceptive specific neurons through a local excitatory, NMDA-dependent neural circuit involving neurons expressing the gamma isoform of protein kinase C. Here, we further investigated the clinical relevance and processing of glycine disinhibition. First, we showed that glycine disinhibition with strychnine selectively induced dynamic but not static mechanical allodynia. The induced allodynia was resistant to morphine. Second, morphine did not prevent the activation of the neural circuit underlying allodynia as shown by study of Fos expression and extracellularsignal regulated kinase phosphorylation in dorsal horn neurons. Third, in contrast to intradermal capsaicin injections, light, dynamic mechanical stimuli applied under disinhibition did not produce neurokinin 1 (NK1) receptor internalization in dorsal horn neurons. Finally, light, dynamic mechanical stimuli applied under disinhibition induced Fos expression only in neurons that did not express NK1 receptor. To summarize, the selectivity and morphine resistance of the glycine-disinhibition paradigm adequately reflect the clinical characteristics of dynamic mechanical allodynia. The present findings thus reveal the involvement of a selective dorsal horn circuit in dynamic mechanical allodynia, which operates through superficial lamina nociceptive-specific neurons that do not bear NK1 receptor and provide an explanation for the differences in the pharmacological sensitivity of neuropathic pain symptoms.
\end{abstract}

Key words: allodynia; disinhibition; glycine; NK1 receptor; morphine; pain

\section{Introduction}

Increased knowledge of pain-generating mechanisms and their translation into symptoms have provided the hope that a dissection of the mechanisms that are at play in each patient could be a reachable goal (Woolf, 2004; Campbell and Meyer, 2006). This, combined with a selection of drugs that act on those mechanisms should make it possible to design optimal treatments for individual patients (Baron, 2006; Knabl et al., 2008). However, difficulties arise considering that in some patients a single mechanism may produce their pain, but in others, multiple mechanisms may contribute (Scholz and Woolf, 2002). Moreover, the same symptom may be generated by a number of mechanisms and a single mechanism may potentially produce different symptoms. To better understand such complex relations, it is crucial to determine how much animal pain models reflect the clinical characteristics

Received Aug. 17, 2008; revised Dec. 22, 2008; accepted Jan. 21, 2009.

This work was supported by funding from INSERM, Ministère de I'Enseignement Supérieur et de la Recherche, and Université d'Auvergne-Clermont1 (France). We thank A. Letagneaux for help with experiments and A. M. Gaydier for secretarial assistance.

Correspondence should be addressed to either Daniel L. Voisin or Radhouane Dallel, INSERM, U929, Neurobiologie de la douleur trigéminale, Faculté de Chirurgie Dentaire, 11 boulevard Charles de Gaulle, 63000 Clermont-Ferrand, France. E-mails: daniel.voisin@inserm.fr or radhouane.dallel@u-clermont1.fr.

D01:10.1523/JNEUROSCI.3923-08.2009

Copyright $\odot 2009$ Society for Neuroscience $\quad$ 0270-6474/09/292519-09\$15.00/0 of pain conditions and to adequately relate mechanisms with individual symptoms in these models.

The mechanisms by which simply brushing the skin can evoke pain in pathological conditions still remain unknown (Campbell and Meyer, 2006). Clinical studies have established that the symptom, called dynamic mechanical allodynia, is mediated by sensory $\mathrm{A} \beta$ fibers normally responsible for the detection of innocuous mechanical stimuli only (Campbell et al., 1988). It also involves alterations in central processing of sensory information by dorsal horn neurons (Woolf and Salter, 2006), including disinhibition through reduced inhibitory transmitter synthesis and/or release (Castro-Lopes et al., 1993; Wiesenfeld-Hallin et al., 1997), loss of inhibitory interneurons (Moore et al., 2002), block of inhibitory receptors (Ahmadi et al., 2002; Harvey et al., 2004), shift in anion gradient (Coull et al., 2005) or altered descending inhibitory modulation from the brain (Vanegas and Schaible, 2004). Glycine inhibitory dysfunction has successfully been used as a model of allodynia (Beyer et al., 1985; Yaksh, 1989; Sherman and Loomis, 1994). We recently found that glycine inhibitory dysfunction gates tactile input to superficial dorsal horn nociceptive specific neurons through protein kinase $\mathrm{C}$ gamma (PKC $\gamma)$-dependent activation of a local, excitatory, NMDA receptor-dependent, dorsal horn circuit (Miraucourt et al., 2007). 
Preclinical and clinical studies have shown that dynamic and static allodynia have different mechanisms (Ochoa and Yarnitsky, 1993; Field et al., 1999a,b; Gonzalez et al., 2000) and respond differently to opiates (Dickenson and Kieffer, 2006). To assess the clinical relevance of glycine disinhibition for dynamic mechanical allodynia, we tested the hypothesis that glycine disinhibition-induced allodynia is selective for one single mechanical modality and compared it to $\mathrm{GABA}_{\mathrm{A}}$ receptordependent disinhibition induced by bicuculline. We also investigated the morphine sensitivity of glycine disinhibition-induced allodynia. Since superficial dorsal horn neurons expressing the neurokinin 1 (NK1) receptor are essential for the development of abnormal pain sensitivity, we also asked whether glycine disinhibition-induced allodynia relies on activation of this neuronal population.

\section{Material and Methods}

Animals. Adult male Sprague Dawley rats (240-280 g) were obtained from Charles River and maintained in a controlled environment (lights on 8:00 A.M.-8:00 P.M., $22^{\circ} \mathrm{C}$ ) with food and water available ad libitum. All efforts were made to minimize the number of animals used. The experiments followed the ethical guidelines of the International Association for the Study of Pain and the European Community Council directive of 24 November 1986 (86/609/EEC).

Chemicals. Unless specifically stated, all chemicals were obtained from Sigma.

Intracisternal injections and behavioral testing. For investigating the effects of morphine upon dynamic mechanical allodynia, animals were briefly $(<3 \mathrm{~min}$ ) anesthetized using a mask with $2 \%$ halothane and received an intracisternal injection of either morphine $(15 \mu \mathrm{g}$ in $5 \mu \mathrm{l}$ aCSF) or aCSF alone ( $5 \mu \mathrm{l}$ ) using a $10 \mu \mathrm{l}$ Hamilton syringe (Miraucourt et al., 2007). aCSF consisted of $150 \mathrm{~mm} \mathrm{Na}^{+}, 3 \mathrm{mM} \mathrm{K}^{+}, 0.8 \mathrm{~mm} \mathrm{Mg}^{2+}, 1.4$ $\mathrm{mm} \mathrm{Ca}{ }^{2+}, 155 \mathrm{~mm} \mathrm{Cl}^{-}$, $\mathrm{pH} 7.4,295 \mathrm{mosmol} \cdot \mathrm{kg}^{-1}$. After recovery $(<2$ $\mathrm{min})$, rats were placed in an observation field $(0.6 \times 0.6 \mathrm{~m}$ square $)$ under red light for a 30 -min habituation session. During this period, rats were adapted to the observation field and red light. The experimenter also reached into the cage to apply gentle air puffing on the face of the animal, to which animals responded with only a simple detection, showing a nonaversive response. Immediately after the $30 \mathrm{~min}$ habituation period, animals were again briefly $(<3 \mathrm{~min})$ anesthetized using a mask with $2 \%$ halothane and received an intracisternal injection of strychnine $(10 \mu \mathrm{g}$ in $5 \mu \mathrm{laCSF}$ ). After recovery ( $<2 \mathrm{~min}$ ), rats were placed in the observation field under red light for a 30-min period test. Gentle air puffing (1-s duration) was applied every 3 min onto the orofacial region using a calibrated pump by a first experimenter. Stimulation was performed when the rat was in a sniffing/no locomotion state: with four paws placed on the ground, neither moving nor freezing. The distance to the target from which the stimulus was applied varied from 2 to $5 \mathrm{~cm}$. The tip of the pump was moved toward the target from behind so that the animal could not see. Each series of stimulation consisted of 5 air puffs applied every $10 \mathrm{~s}$.

For investigating static allodynia, rats were habituated to stand on their hindpaws on the experimenter sleeve and lean against the experimenter chest in a quiet room under red light, according to a method adapted from Ren (1999). The habituation required half an hour during which the animals were tested with von Frey filaments onto a region between the right vibrissa pad and the upper right lip, with carefully avoiding touching any of the vibrissa. Ascending and descending series of von Frey filaments (1.0-12 g; Bioseb) were used. Each filament was tested five times at intervals of at least $5 \mathrm{~s}$. The habituation session was repeated for $2 \mathrm{~d}$. At the end of the second habituation session, all rats responded to $6.0 \mathrm{~g}$ von Frey filament with only a simple detection, showing a nonaversive response. At this time, one rat was excluded from the study because of excessive stress behavior. On the third day, the actual testing session took place. Animals were briefly $(<3 \mathrm{~min})$ anesthetized using a mask with $2 \%$ halothane and received an intracisternal injection of either strychnine $(10 \mu \mathrm{g}$ in $5 \mu \mathrm{l} \mathrm{aCSF})$ or aCSF alone $(5 \mu \mathrm{l})$ using a $10 \mu \mathrm{l}$
Hamilton syringe. After recovery $(<2 \mathrm{~min})$, rats were gently placed on the experimenter's sleeve in a quiet room under red light. Static mechanical stimuli were applied using a $6.0 \mathrm{~g}$ von Frey filament onto a region between the right vibrissa pad and the upper right lip. Stimuli were administered when the rat was immobile on the experimenter's sleeve, with its head directed toward the experimenter's elbow. Series of stimuli were applied every $3 \mathrm{~min}$ for $30 \mathrm{~min}$. Each series of stimuli consisted of 5 stimuli, each tested at an interval of at least $10 \mathrm{~s}$.

In all cases, the behavioral responses were observed and quantified by a second experimenter, according to the method developed by Vos et al. (1994). The evaluating experimenter was blind to the experimental group. A rat's response to mechanical stimulation consisted of one or more of the following elements: (1) detection: rats turn head toward stimulus; (2) withdrawal reaction: rats turn head away or pulls it briskly backward when stimulation is applied (a withdrawal reaction is assumed to include a detection element preceding the head withdrawal and therefore consists of two responses elements); (3) escape/attack: rats avoid further contact with the stimulus, either passively by moving their body away from the stimulus, or actively by attacking the tip of the pump or the hair; (4) asymmetric grooming: rats display an uninterrupted series of at least three wash strokes directed to the stimulated area. The following rank-ordered descriptive responses categories were formulated according to the study by Vos et al. (1994): no response, nonaversive response, mild aversive response, strong aversive response, prolonged aversive behavior. Each category was given a score $(0-4)$ based on the number of observed response elements. According to Vos et al. (1994), the score was assumed to reflect the magnitude of the aversiveness evoked by the mechanical stimulation. Score was equal to zero in case of absence of response. A mean score value was then calculated for each stimulation series.

Medullary dorsal horn microinfusion and arterial blood pressure recordings. We were unable to investigate orofacial dynamic and static allodynia after intracisternal injections of the $\mathrm{GABA}_{\mathrm{A}}$ receptor antagonist bicuculline in freely moving rats, due to the deleterious cardiovascular and respiratory effects (including apnea) intracisternally injected bicuculline induced. We thus studied the effects of brushing and von Frey hair application on the lip of anesthetized rats on arterial blood pressure recordings after bicuculline microinfusion within the medullary dorsal horn (MDH). With such a method, cardiovascular responses evoked by nonnoxious stimuli can be compared with those evoked by nociceptive stimuli (Yamamura et al., 1999; Miraucourt et al., 2007).

Rats were anesthetized deeply with urethane $(1.5 \mathrm{~g} / \mathrm{kg}$, i.p. $)$ as previously described (Miraucourt et al., 2007), and the carotid artery was cannulated. The arterial catheter was attached to a calibrated pressure transducer (UFI) connected to an amplifier (Stoelting) for continuous monitoring of the mean arterial blood pressure (MAP). The analog output from the blood pressure amplifier was connected to a computer data sampling system (Cambridge Electronics Design 1401 computer interface). Cutaneous vascularization was periodically checked by observing the color of the paw extremities and the rapidity by which they regained normal color after pressure application. Core temperature was maintained at $37 \pm 0.5^{\circ} \mathrm{C}$ with a homeothermic blanket system.

Animals were then placed in a stereotaxic frame with the head fixed in a ventroflexed position (incisor bar dropped $5 \mathrm{~mm}$ under the standard position) by means of an adapted metallic bar. For microinjection into the $\mathrm{MDH}$, the skin and muscles overlying the occipital bone were removed. A cervical laminectomy and suboccipital craniotomy were performed to expose the medulla. The dura mater was then opened and the medulla was stabilized by a stainless-steel frame held in position with a micromanipulator and a 2\% Ringer-agar gel.

Drugs were delivered in the MDH by two-barrel glass micropipettes (3GC120F-15; Clark Electromedical Instruments) fixed on the micromanipulator and connected to two Hamilton syringes $(1 \mu \mathrm{l})$ by means of polyethylene tubing (Dallel et al., 1998). The micropipette was broken back maximally to a diameter of $70-100 \mu \mathrm{m}$. The micropipettes and tubing were filled with $\mathrm{GABA}_{\mathrm{A}}$ antagonist bicuculline methiodide (50 $\mu \mathrm{mol}$ in $0.5 \mu \mathrm{laCSF}$ ) or aCSF with pontamine sky blue, respectively (for location of the injection site). Injections of drugs were performed with a manual injector over a period of $2 \mathrm{~min}$ and monitored by observing the 
movement of an air bubble in the tubing. The slow rate of injection was chosen to minimize the chance of tissue damage. The micropipettes remained in place throughout the experimental session. The dose of bicuculline was selected based on published reports (Roberts et al., 1986; Malan et al., 2002). Fresh bicuculline solution was prepared every testing day.

Responses to mechanical stimulation of the skin were determined by applying brief (10 s) innocuous stimulation to the animal upper lip using either a soft paintbrush or a $6 \mathrm{~g}$ von Frey hair.

Immunocytochemistry. In a first group of rats, the effects of morphine upon Fos expression and extracellular-signal regulated kinase (ERK) phosphorylation after brushing of the upper lip under strychnine were investigated. ERK activation within the $\mathrm{MDH}$ in response to innocuous orofacial tactile stimuli after intracisternal injection of aCSF only was also investigated. Rats were anesthetized deeply with urethane ( $1.5 \mathrm{~g} / \mathrm{kg}$, i.p.) as previously described (Voisin et al., 2005). Twenty minutes after the injection, the depth of the anesthesia was tested, and rats received a subcutaneous injection of either morphine $\left(4 \mathrm{mg} \cdot \mathrm{kg}^{-1}\right.$, in $200 \mu \mathrm{l}$ isotonic saline) or saline alone $(200 \mu \mathrm{l})$. Twenty-five minutes later, rats received an intracisternal injection of strychnine ( $40 \mu \mathrm{g}$ in $5 \mu \mathrm{laCSF}$ ) or aCSF only $(5 \mu \mathrm{l})$. This was followed 5 min later by innocuous stimulation of the right upper lip using a soft paintbrush at 0.5 stroke/s for 10 (Fos expression) or 2 min (ERK phosphorylation). For Fos and ERK experiments, rats were killed $2 \mathrm{~h}$ and 2 min later, respectively, their brain fixed and cut. Free-floating brainstem sections were placed in $2 \%$ normal goat serum for $1 \mathrm{~h}$ before incubation in a rabbit antibody directed against Fos (1:1000, $48 \mathrm{~h}, 4^{\circ} \mathrm{C}$, Oncogene Science) or phospho p44/42 MAP kinase (1:2000, $24 \mathrm{~h}$, room temperature, Cell Signaling Technology), and a secondary goat anti-rabbit antibody (1:400, $2 \mathrm{~h}$, Jackson Immunoresearch). Immunoreactivity for Fos and phospho-ERK was visualized using nickel-DAB.

In a second group or rats, we investigated whether light, dynamic mechanical stimuli applied under strychnine evokes substance $P$ release, which was measured by NK1 receptor internalization (Honore et al., 1999). This was compared with the well known substance $P$ release evoked by intradermal capsaicin injection. In the strychnine subgroup, animals were stimulated in the same conditions as in the first group after intracisternal strychnine injection, but did not receive morphine or aCSF previously. In the capsaicin subgroup, animals were anesthetized as in the first group and received a right upper lip subcutaneous injection of capsaicin ( $25 \mu \mathrm{g}$ in $25 \mu \mathrm{l}$ endolipid) using a $30 \mathrm{G}$ gauge needle. The injection was made a few millimeters inside the tissue to ensure the diffusion into the superficial layers of the epidermis, where nociceptor terminations are found. In both subgroups rats were killed and perfused $10 \mathrm{~min}$ after the end of the stimulus. Free-floating brainstem sections were placed in $2 \%$ normal goat serum for $1 \mathrm{~h}$ before incubation in a rabbit antibody directed against the NK1 receptor $(1: 2500,24 \mathrm{~h}$, room temperature, Biochemicals) and a secondary Cy2 conjugated goat anti-rabbit (1:200, $30 \mathrm{~min}$, room temperature, Jackson Immunoresearch).

In a third group of rats, Fos expression in NK1 receptor-expressing dorsal horn neurons was studied. Animals were stimulated and killed in the same conditions as in the first group after intracisternal strychnine injection but did not receive morphine or aCSF previously. Animals of the control subgroup did not receive intracisternal strychnine but aCSF only. Brainstem sections underwent free-floating sequential immunostaining for Fos and the NK1 receptor. Primary rabbit antibodies specific for the NK1 receptor (1:2500, $48 \mathrm{~h}$, Biochemicals) and a secondary goat anti-rabbit antibody (1:400, $2 \mathrm{~h}$, Jackson Immunoresearch) were used. Immunoreactivity for the NK1 receptor was visualized using DAB only.

In all cases, rats were killed at appropriate time under deep anesthesia and perfused transcardially with warm $\left(37^{\circ} \mathrm{C}\right)$ heparinized saline $(25 \mathrm{IU}$ heparin $/ \mathrm{ml})$ followed by cold $\left(10^{\circ} \mathrm{C}\right)$ phosphate-buffered solution $(0.1 \mathrm{M}$, $\mathrm{pH}$ 7.6) containing $4 \%$ paraformaldehyde and $0.03 \%$ picric acid for 15 min. The brainstem was then removed and transferred into phosphatebuffered solution containing $30 \%$ sucrose at $4^{\circ} \mathrm{C}$ and left overnight. Coronal sections $(30 \mu \mathrm{m})$ were cut on a freezing microtome and collected in a $0.05 \mathrm{M}$ Tris-buffered saline (TBS) before being processed. In all cases, sections were rinsed in TBS several times, between and after each incubation, and finally transferred onto gelatinized slides before being coverslipped using DPX. All immunolabels were diluted in TBS containing $0.25 \%$ bovine serum albumin and $0.3 \%$ Triton X-100. Specificity controls consisted of the omission of the primary antibody and incubation of sections in inappropriate secondary antibodies. In all these control experiments, no specific staining was evident. A few selected sections were mounted separately and slightly counterstained with cresyl violet to help delineate the limits of the MDH.

For data analysis, computer-assisted bright-field images of representative labeling were obtained using a charge-coupled device color video camera (Sony DXC-950P) connected to a Nikon Optiphot-2 microscope. Images were exported to Adobe PhotoShop (CS2) to adjust brightness and contrast before adjusting the image scale. NK1 receptor immunofluorescence was analyzed using a motorized Zeiss Axioplan 2 Imaging microscope coupled with a Hamamatsu C4742-95 digital camera, by switching between FITC and Texas Red filter sets. In cell bodies that do not contain internalized NK1 receptors, the immunoreactivity for NK1 receptor is uniformly distributed on the cell surface. In contrast, in the neurons that have internalized the NK1 receptors, the cytoplasm contains bright, immunofluorescent endosomes. In the present study, neurons containing 10 or more endosomes were considered to be internalized (Honore et al., 1999). For illustrations, numerical images of immunofluorescence were deconvoluted using MetaMorph 5.4 software. Fos immunoreactive nuclei, NK1 receptor-expressing neurons and duallabeled cells were counted in each rat according to their location in the different laminae of the MDH from 7 different sections, each taken at a given rostrocaudal plane within the $\mathrm{MDH}$ (from 0 to $-2160 \mu \mathrm{m}$ at 360 $\mu \mathrm{m}$ intervals). Cell bodies with internalized and not internalized NK1 receptors were counted in each rat according to their location in the different laminae of the MDH from 5 different sections (from -360 to $-1800 \mu \mathrm{m}$ at $360 \mu \mathrm{m}$ intervals). Brainstem sections were categorized according to their approximate rostrocaudal location from the MDHsubnucleus interpolaris junction. Sections to be counted were chosen according to their macroscopic matching to each given rostrocaudal plane within the MDH. Intervals of $360 \mu \mathrm{m}$ between planes ensured that cells were counted only once. Counts were performed by an experimenter who was blind to the experimental group. The delineation of the MDH was based upon the atlas of Paxinos and Watson (1997) and our own myeloarchitectural atlas. The data are expressed as the sum of the total number of labeled cells counted from all sections that were analyzed in each animal.

Statistical analysis. For data analysis, ANOVA for repeated measures followed by Dunnett's or Newman-Keuls tests were used and the level of significance was set at $p<0.05$. Results are expressed as mean \pm SEM.

\section{Results}

\section{Strychnine induces morphine-resistant dynamic, but not} static, mechanical allodynia

As previously reported (Miraucourt et al., 2007), intracisternal injection of strychnine ( $10 \mu \mathrm{g}$ in $5 \mu \mathrm{laCSF}$ ) produced a dramatic face dynamic mechanical allodynia with the highest mean score reaching $3.2 \pm 0.1(n=5)$ on a scale ranging from 0 to 4 (Fig. $1 A)$. Allodynia started immediately after the injection and lasted for $15 \mathrm{~min}$. Scores in animals that received a preemptive administration of morphine ( $15 \mu \mathrm{g}$ in $5 \mu \mathrm{l} \mathrm{aCSF} ; n=4)$ were not significantly different from scores in control rats that received aCSF only (Fig. 1A).

To assess static allodynia, we used a $6.0 \mathrm{~g}$ von Frey filament, since this was the highest stimulus intensity that evoked a nonaversive response in habituated rats. Intensity-response relationship for different intensities near the aversive threshold showed that $6.0 \mathrm{~g}$ was the value that induced a mean response halfway between detection ( score $=1$ ) level and mild aversive response (score $=2$ ) level (Fig. 1B). Intracisternal injection of strychnine ( $10 \mu \mathrm{g}$ in $5 \mu \mathrm{laCSF}$ ) did not change significantly response scores to face stimulation with a $6 \mathrm{~g}$ von Frey hair, although a slight increase to $1.7 \pm 0.4$ was found at 6 and 9 min postinjection, respectively (Fig. $1 A$ ). Scores in animals that received strychnine 
were similar to scores in control rats that received aCSF only $(n=5)$. Throughout the testing session, response scores remained at the nonaversive level found on the second habituation session (data not shown), indicating that no static mechanical allodynia developed under strychnine.

\section{Bicuculline induces cardiovascular} responses to orofacial stimulation that reflect static, but not dynamic, allodynia As previously described (Miraucourt et al., 2007), we used arterial blood pressure recordings to evaluate the effects of brushing and von Frey hair application on the lip of anesthetized rats after bicuculline microinfusion within the superficial laminae of the MDH. The blood pressure of the animal remained unchanged during $\mathrm{MDH}$ bicuculline application and light brushing of the lip as well, both before and after bicuculline (Fig. 2) $(n=4)$. Since changes in blood pressure provide a reliable index of nociception in anesthetized animals (Yamamura et al., 1999), innocuous dynamic mechanical stimuli were not regarded as nociceptive under these circumstances.

In contrast, microinfusion of bicuculline within the $\mathrm{MDH}$ $(n=4)$ significantly and reversibly increased blood pressure in response to face stimulation with a $6 \mathrm{~g}$ von Frey hair (Fig. 2). The effect of bicuculline lasted for $25 \mathrm{~min}$. Thus, when $\mathrm{GABA}_{\mathrm{A}}$ receptor-mediated inhibition was blocked within the $\mathrm{MDH}$, innocuous static mechanical stimuli were regarded as nociceptive.

\section{Morphine does not prevent the activation of the neural circuit underlying dynamic mechanical allodynia}

As previously reported (Miraucourt et al., 2007), after intracisternal injection of strychnine ( $40 \mu \mathrm{g}$ in $5 \mu \mathrm{l} \mathrm{aCSF}$ ) in urethane anesthetized rats, light sweeping of the upper lip with a soft paintbrush (10 min, $0.5 \mathrm{~Hz}$ ) resulted in strong, ipsilateral Fos expression in the superficial laminae of the MDH (Fig. $3 A$ ), but not in the deep laminae, and not in the contralateral side. Fos expression was predominant in lamina $I$, in the most superficial outer part of lamina II (laminae I-IIo), in the inner part of lamina II (IIi) and in the outer part of lamina III (IIIo) (Fig. 3B). Fos expression in animals that received a preemptive subcutaneous administration of morphine $\left(4 \mathrm{mg} \cdot \mathrm{kg}^{-1}\right)$ was qualitatively (Fig. $3 A$ ) and quantitatively similar (Fig. $3 B$ ) to Fos expression in control rats that received aCSF ( $n=4$ in each group). Thus, brush induced Fosexpression under pharmacological removal of glycine inhibition was not altered by morphine.

ERK can rapidly and specifically be activated by peripheral noxious stimuli within spinal dorsal horn neurons and mediate pain hypersensitivity (Ji et al., 1999). ERK is also activated in a somatotopic and lamina-specific way within the MDH in response to noxious peripheral orofacial stimuli, strikingly reminiscent to that observed in the spinal cord (Noma et al., 2008). After intracisternal injection of strychnine ( $40 \mu \mathrm{g}$ in $5 \mu \mathrm{laCSF})$ in urethane anesthetized rats, light sweeping of the upper lip with a soft paintbrush ( $2 \mathrm{~min}, 0.5 \mathrm{~Hz}$ ) resulted in strong, ipsilateral ERK phosphorylation in the superficial laminae of the $\mathrm{MDH}$ (Fig. 3A), but not in the deep laminae, and not in the contralateral side. Immunostaining was localized within dendrites, soma cytoplasm
B

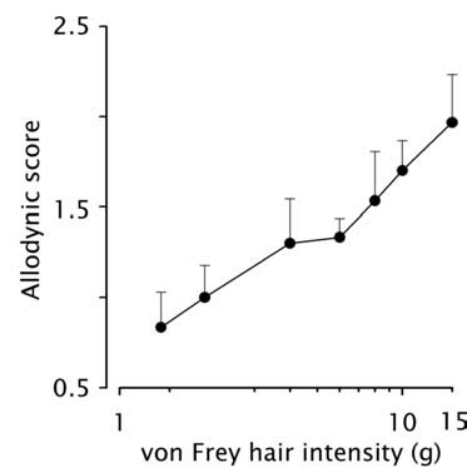

Air puff $\left\{\begin{array}{l}-- \text { aCSF-Strychnine } \\ -\infty \text { Morphine-Strychn }\end{array}\right.$

von Frey $\rightarrow-$ Strychnine

$\rightarrow-$ aCSF

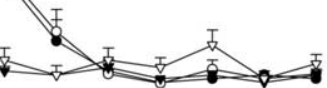

15

5

inection (min)

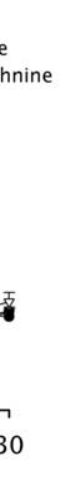

Figure 1. Glycine disinhibition induces morphine-resistant dynamic, but not static, mechanical allodynia. $\boldsymbol{A}$, The time course of in behavioral responses evoked by dynamic mechanical stimuli (air puff) applied on the face of intracisternally strychnine injected rats is shown. Rats were preemptively injected into the cisterna magna with either morphine or aCSF 30 min before face of intracisternally aCSF or strychnine injected rats is also shown. Graphs represent the mean response ( $+S E M)$ of rats ( $n=4-5$ /group) to 5 stimuli applied at 10 s intervals. $\boldsymbol{B}$, Intensity-response relationship for different von Frey hairs near the aversive threshold. Graph represents the mean response ( \pm SEM) of rats $(n=6)$ to 5 stimuli applied at 10 s intervals.

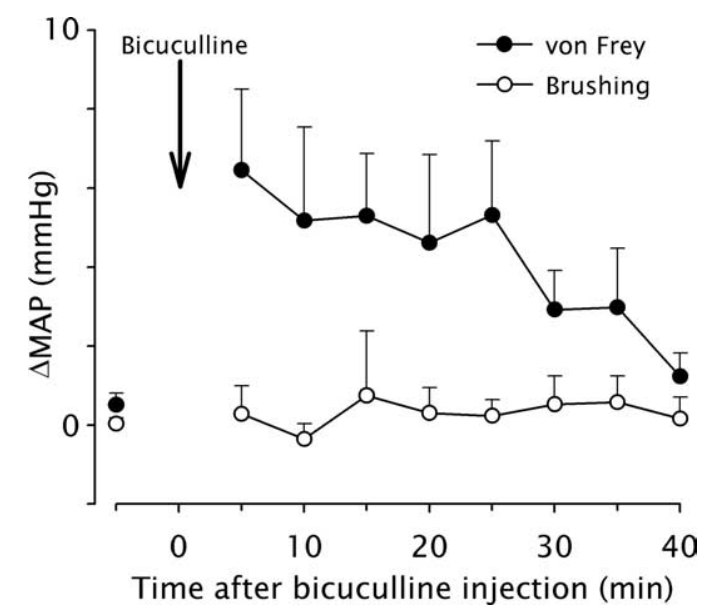

Figure 2. $\mathrm{GABA}_{\mathrm{A}}$ receptor-dependent disinhibition induces cardiovascular responses that reflect static, but not dynamic, allodynia. The time course of changes in arterial blood pressure responses ( $\triangle$ MAP) evoked by dynamic (light brushing) or static $(6.0 \mathrm{~g}$ von Frey hair) mechanical stimuli applied on the face of anesthetized rats immediately after microinfusion of bicuculline within the MDH is shown. Graphs represent the mean response ( \pm SEM) of rats ( $n=4 /$ group) to 10 s long stimuli. Bicuculline significantly and reversibly increased blood pressure in response to face stimulation with a $6 \mathrm{~g}$ von Frey for $25 \mathrm{~min}$ after application.

and nuclei. ERK phosphorylation was distributed like Fos expression and predominated in lamina $\mathrm{I}$, in the most superficial outer part of lamina II (laminae I-IIo), in the inner part of lamina II (IIi) and in the outer part of lamina III (IIIo) (Fig. 3B). The distribution of ERK phosphorylation in animals that received a preemptive subcutaneous administration of morphine $(4 \mathrm{mg}$ $\mathrm{kg}^{-1}$ ) was qualitatively (Fig. $3 A$ ) and quantitatively similar (Fig. $3 B$ ) to the distribution of ERK phosphorylation in control rats that received aCSF ( $n=4$ in each group). In contrast, ERK was not activated within the $\mathrm{MDH}$ in response to innocuous orofacial tactile stimuli after intracisternal injection of aCSF only $(n=3)$ (Fig. $3 B$ ). Thus, after pharmacological removal of glycine inhibition, brush induced ERK activation that was not altered by morphine. 
A

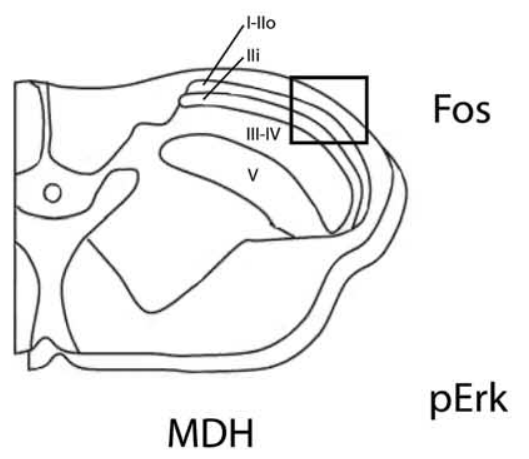

Vehicle
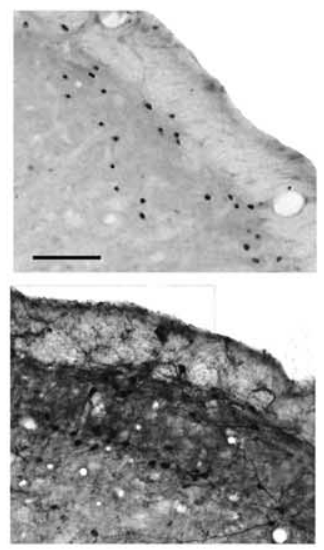

Morphine
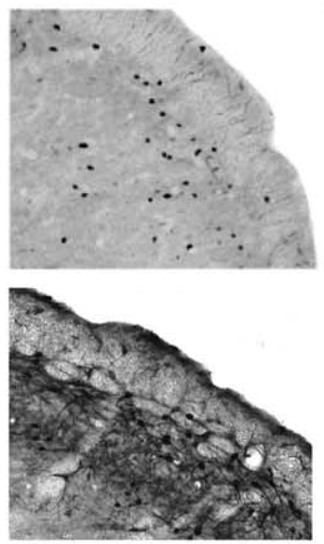

B

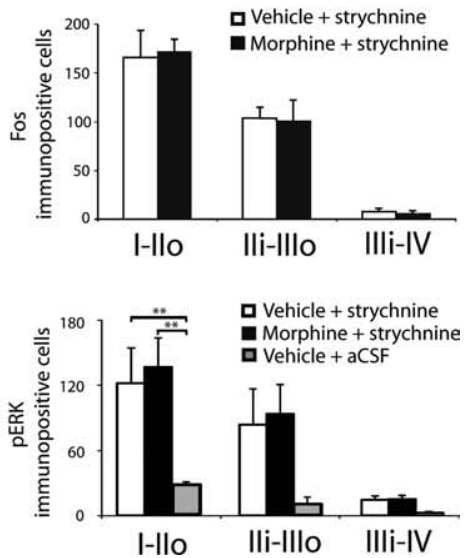

Figure 3. Morphine does not prevent the activation of the neural circuit underlying dynamic mechanical allodynia. $A$, Images of Fos-positive cell nuclei and phospho-ERK immunolabeling in the MDH of control (Vehicle) and morphine injected rats. Fos expression and ERK phosphorylation were induced by light brushing of the ipsilateral lip after intracisternal strychnine; subcutaneous morphine $\left(4 \mathrm{mg} \cdot \mathrm{kg}^{-1}\right)$ or vehicle (isotonic saline) were preemptively administered $25 \mathrm{~min}$ before strychnine; scale bar, $50 \mu \mathrm{m}$. On the left, the approximate location at which images were taken is indicated on the schematic diagram of a coronal section of the MDH. $\boldsymbol{B}$, Bar histograms summarizing mean Fos expression and ERK phosphorylation in the different laminae of the ipsilateral MDH after light brushing of the lip after intracisternal injection of strychnine or aCSF in vehicle and morphine injected animals ( $n=3-4 /$ group). $\boldsymbol{A}, \boldsymbol{B}, \mathrm{I}-\|_{0}$, Laminae $\mathrm{I}$ and outer II; III-IIIO, laminae inner II and outer III; III-IV, laminae inner III and IV. ${ }^{* *} p<0.01$.

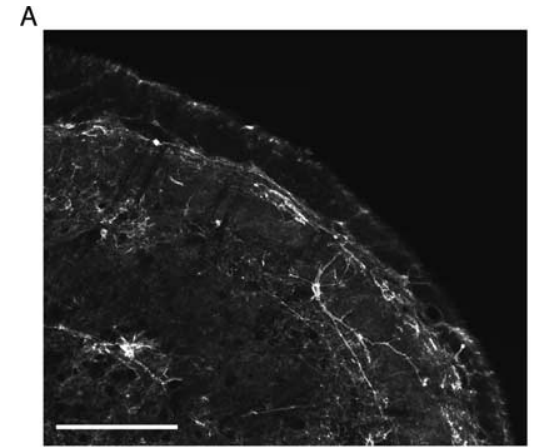

B

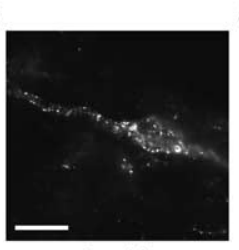

Capsaicin

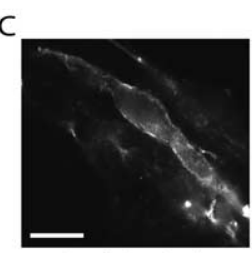

Strychnine - Brush
D

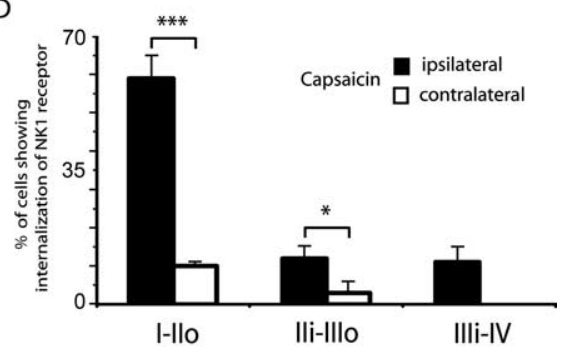

E

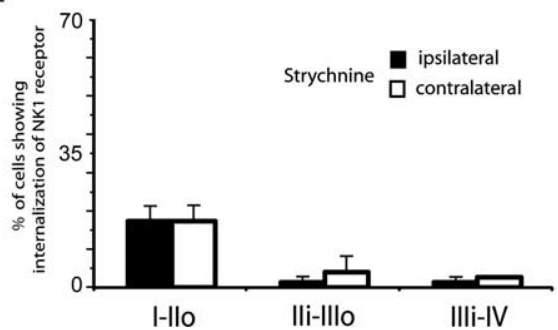

Figure 4. Unlike capsaicin, light, dynamic mechanical stimuli applied under glycine disinhibition do not produce NK1 receptor internalization in dorsal horn neurons. $\boldsymbol{A}$, Image of NK1 receptor-expressing neurons in the MDH as revealed by immunofluorescence. $\boldsymbol{B}$, Numerical image illustrating a lamina I MDH neuron internalizing NK1 receptors in response to injection of capsaicin in the upper lip. C, Numerical image illustrating a lamina I NK1 immunopositive neuron in the MDH of a rat in which light brushing of the ipsilateral lip was applied after intracisternal strychnine. Scale bars: $\boldsymbol{A}, 200 \mu \mathrm{m} ; \boldsymbol{B}, \boldsymbol{C}, 10 \mu \mathrm{m}$. $\boldsymbol{D}$, Bar histograms summarizing the percentage of neurons internalizing the NK1 receptor in the different laminae of the MDH after capsaicin injection into the lip. $\boldsymbol{E}$, Bar histograms summarizing the percentage of neurons internalizing the NK1 receptor in the different laminae of the MDH after brushing of the lip under strychnine. D, E, I-Ilo, Laminae I and outer II; IIi-IIlo, laminae inner II and outer III; IIIi-IV, laminae inner III and IV; ${ }^{*} p<0.05,{ }^{* * *} p<0.001$.

Light, dynamic mechanical stimuli applied under strychnine do not produce NK1 receptor internalization in dorsal horn neurons

As previously described (Brown et al., 1995; Coste et al., 2008), the lamina I of the MDH contained many heavily labeled NK1 receptor immunoreactive neurons, while the inner part of lamina II was noticeably devoid of NK1 receptor immunoreactive cells. A distinct band of labeling was located in the dorsal part of lamina
III and a few immunoreactive neurons were also found in the deeper lamina $\mathrm{V}$ (Fig. 4A). To provide a positive control, in 4 animals, $25 \mu$ l of $0.1 \%$ capsaicin solution were injected in the right upper lip $10 \mathrm{~min}$ before they were perfused with fixative. As previously reported (Mantyh et al., 1995), the noxious stimulus produced strong internalization of the NK1 receptor in ipsilateral lamina I cell bodies, as evidenced by the increase in the proportion of cell bodies exhibiting NK1 receptor endosomes from $10 \pm 1 \%$ (contralateral side) to $59 \pm$ $6 \%$ (ipsilateral side), and in dendrites located in lamina I and II (Fig. 4B,D). It induced detectable internalization only in a few cell bodies located ventral to the lamina II-III border (Fig. 4D). In contrast to the results of capsaicin injections, light, dynamic mechanical stimuli applied under strychnine in 4 other rats did not produce significant changes in NK1 receptor internalization in dorsal horn neurons (proportion of lamina I cell bodies exhibiting NK1 receptor endosomes $=13 \pm$ $3 \%$ ) compared with basal levels of internalization measured in the contralateral side (Fig. 4C,E). Strychnine-induced dynamic mechanical allodynia thus, although relying on the recruitment of superficial lamina nociceptive-specific neurons, does not operate through NK1 receptor activation.

NK1 receptor-expressing dorsal horn neurons are not activated by brushing under strychnine

In 4 animals which underwent light sweeping of the upper lip with a soft paintbrush $(10 \mathrm{~min}, 0.5 \mathrm{~Hz})$ under strychnine, we counted the number of NK1 receptor-bearing neurons in the 
population of Fos-expressing cells. We found a very small number of double-labeled neurons (Fig. 5), similarly to the control situation $(n=4)$. In contrast, capsaicin injection into the upper lip $(n=3)$ resulted in a significantly higher expression of Fos in NK1 receptor-bearing neurons of the superficial laminae of the $\mathrm{MDH}$ (Fig. 5). Altogether, these results suggest that light dynamic mechanical stimuli applied under strychnine do not recruit NK1expressing neurons in the superficial dorsal horn.

\section{Discussion}

In this study, we sought to determine how much glycine inhibitory dysfunction reflects the clinical characteristics of dynamic mechanical allodynia, a prominent feature of neuropathic, inflammatory and postoperative pain. The present results show that glycine disinhibition induces selectively a dynamic mechanical allodynia that is resistant to morphine. These features are clinically relevant, suggesting that glycine disinhibitory mechanisms could be at work in patients too (Scholz and Woolf, 2002; Zeilhofer and Zeilhofer, 2008). The data also shows that although touch can activate pain by recruiting superficial dorsal horn nociceptive neurons, this does not operate through NK1 receptor activation and not through NK1 receptor-bearing neurons (Fig. 6). Thus, involvement of distinct dorsal horn circuits could explain differences in the pharmacological sensitivity of dynamic mechanical allodynia.

Two kinds of mechanical allodynia can be clearly discerned by clinical criteria in patients with neuropathic syndromes or after skin injurious stimuli (Ochoa and Yarnitsky, 1993). A dynamic type can be elicited by lightly stroking the skin and a static type can be elicited by applying gentle pressure on it. It is established in patients as well as in experimental models of neuropathic pain that dynamic mechanical allodynia is mediated by peripheral large myelinated A $\beta$ fibers (Ochoa and Yarnitsky, 1993; Field et al., 1999b). The sensory A $\beta$ fibers normally do not produce pain and are responsible for the detection of innocuous mechanical stimuli only (Torebjörk et al., 1987). After nerve or tissue injury, however, activation of these afferents elicits pain (Woolf and Salter, 2006). In contrast, static allodynia, which manifests by heightened pain associated with application of small, stiff or sharp probes to the skin such as von Frey monofilaments, is predominantly mediated by A $\delta$ fibers (Ochoa and Yarnitsky, 1993; Field et al., 1999a,b). Our results show that glycine disinhibition selectively induced dynamic, but not static mechanical allodynia. Accordingly, previous studies (Game and Lodge, 1975; Sorkin and Puig, 1996) did not find evidence for strychnine modulation of dorsal horn neuron activity elicited directly by stimulation recruiting smaller diameter fibers. This suggests that under physiological conditions, glycine inhibition in the dorsal horn is selective for $\mathrm{A} \beta$ input. However, recent findings suggest that under pathological conditions, additional pathways might be recruited and reduced glycinergic inhibition might then also affect the relay of nociceptive signals (Ahmadi et al., 2002; Harvey et al., 2004).

In the present work, we were able to replicate our previous findings that light brushing of the lip under glycine-disinhibition results in strong, ipsilateral Fos expression, in the superficial laminae of the MDH (Miraucourt et al., 2007). In addition, we show for the first time that ERK can be activated in the dorsal horn in response to innocuous dynamic mechanical stimulation under glycine-disinhibition. Interestingly, ERK phosphorylation was distributed like Fos expression, adopting a pattern involving not only the outer part of the superficial laminae, as previously found in other models of neuropathic pain (Liu et al., 2004; Zhuang et al., 2005; Matsumoto et al., 2008), but also the cellular region that overlaps the border between lamina II and III. Both Fos and ERK results strengthen the idea that a normally silent dorsal horn circuit can be recruited to allow the transfer of $A \beta$ input from the border between lamina II-III, where low threshold A $\beta$ mechanoreceptive afferents extend their arbors (Woolf, 1987; Todd and Koerber, 2006), to nociceptive neurons in the superficial laminae (Miraucourt et al., 2007; Neumann et al., 2008). Under pathological conditions or after removal of glycine inhibition, the circuit could be activated to convert touch into pain (Keller et al., 2007). In the dorsal horn, the neuroplastic changes associated with increased pain sensitivity represent a highly complex orchestration of signaling transduction cascades, receptors and gene expression changes (Woolf and Salter, 2006). ERK is a strong candidate in the establishing and maintaining nociceptive induced neuroplasticity (Ji, 2004). Our findings suggest that ERK activation in dorsal horn neurons is involved in the expression of abnormal pain after disinhibition.

The present results are also consistent with previous reports on the failure of morphine given at the segmental level, at doses close to the one we used, to block dynamic mechanical allodynia induced by glycine disinhibition (Yaksh, 1989; Sherman and Loomis, 1994; Lee et al., 1995), an observation that we now extend by showing that systemic morphine did not modify dorsal horn touch-evoked Fos expression and ERK phosphorylation. The subcutaneous dose of morphine we used $\left(4 \mathrm{mg} \cdot \mathrm{kg}^{-1}\right)$ has been shown to reduce noxious stimulus-induced Fos expression in the spinal and medullary dorsal horns consistently (Presley et al., 1990; Nozaki et al., 1992; Nojima et al., 2003). Our findings are thus in coherence with the suggestion that glycine inhibition in the dorsal horn is selective for $\mathrm{A} \beta$ input. Indeed, it has been shown that opioid receptors are mainly located on thin primary afferent fibers (Lamotte et al., 1976; Besse et al., 1990) and that morphine can block $\mathrm{C}$ and $\mathrm{A} \delta$ but not $\mathrm{A} \beta$ fiber-evoked responses into the dorsal horn (Le Bars et al., 1976; Dickenson and Sullivan, 1986; Sorkin and Puig, 1996, Dallel et al., 1998). Other studies have shown that thermal hyperalgesia and static allodynia induced by nerve injury are sensitive to systemic morphine, while the accompanying dynamic allodynia is resistant to morphine (Bian et al., 1995; Lee et al., 1995; Field et al., 1999a; Gonzalez et al., 2000; Catheline et al., 2001). The inefficiency of morphine on dynamic mechanical allodynia could be explained by the fact that pain results from pathways where opioid receptors do not control activity (Dickenson and Kieffer, 2006).

Our internalization study showed that glycine inhibitory dysfunction did not turn touch into pain through NK1 receptor activation. Accordingly, several authors failed to detect internalization of the NK1 receptor after stimulation of $\mathrm{A} \beta$ fibers (Allen et al., 1999; Malcangio et al., 2000; Hughes et al., 2007). It has been proposed that substance $\mathrm{P}$ is upregulated in low-threshold myelinated primary afferents after certain types of nerve injury, and that release of substance $P$ from these afferents contributes to the resulting allodynia (Noguchi et al., 1995; Devor, 2006; but see Ruscheweyh et al., 2007). This clearly cannot be the case in the present study. Furthermore, several groups also did not detect any $\mathrm{A} \beta$-evoked NK1 receptor internalization in neurons from the dorsal horn in spinal nerve ligation and chronic constriction injury models of neuropathic pain (Allen et al., 1999; Malcangio et al., 2000; Hughes et al., 2007) (but see Malcangio et al., 2000 for the spinal nerve lesion model). This suggests that any release of substance $\mathrm{P}$ from $\mathrm{A} \beta$ afferents is unlikely to activate dorsal horn NK1 receptors and contribute to dynamic mechanical allodynia. Accordingly, in the sciatic chronic constrictive injury model of neuropathic pain selective antagonism of the NK1 receptor 
A
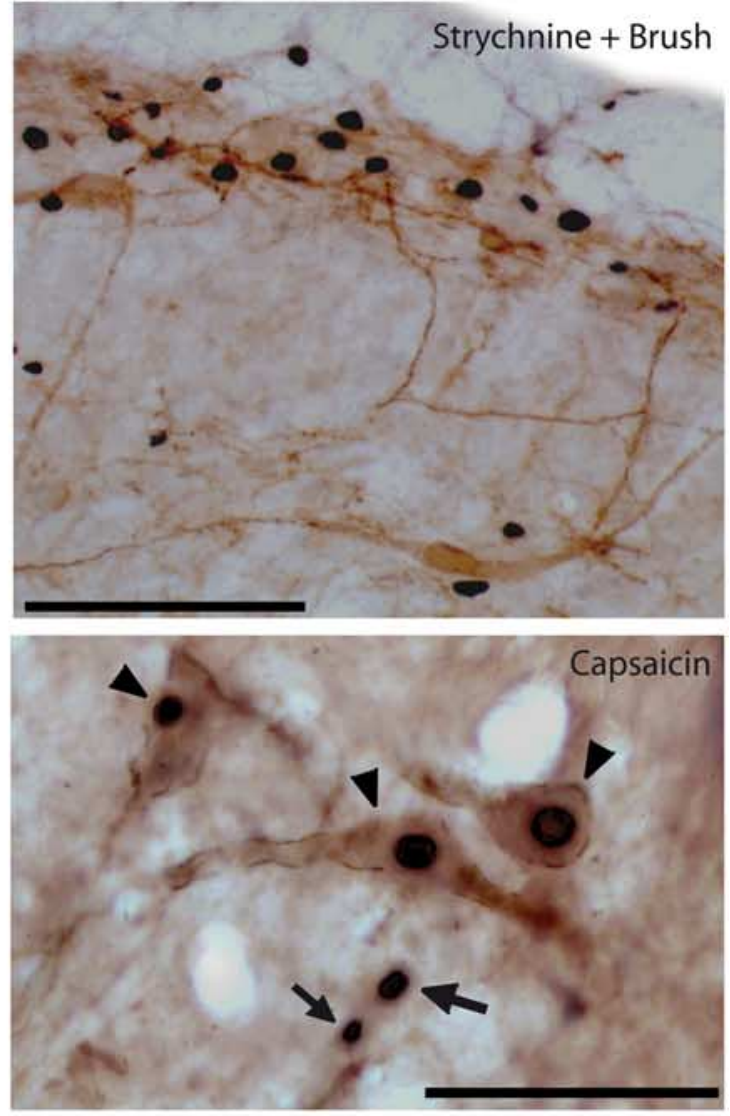

B
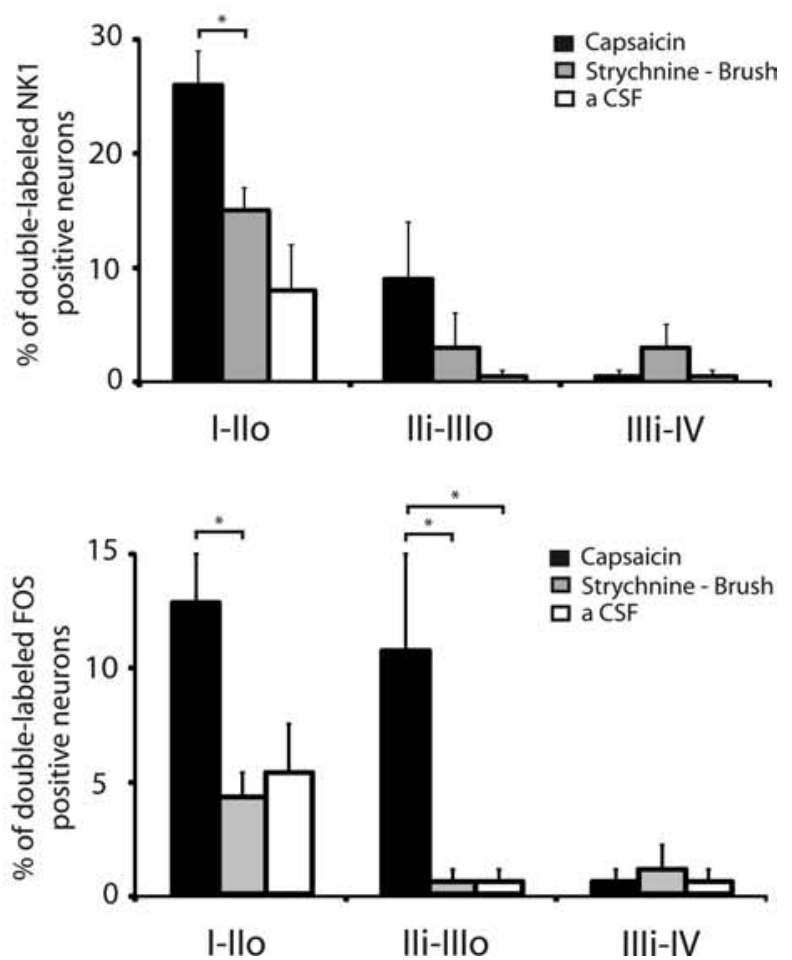

Figure 5. Rare NK1 receptor-expressing dorsal horn neurons are activated by brushing under glycine disinhibition compared with capsaicin injection. $\boldsymbol{A}$, Images of Fos-positive cell nuclei (black nuclear staining) and NK1 receptor-expressing neurons (brown staining) in lamina I-III of the MDH. Top, After brushing under glycine disinhibition; scale bar, $100 \mu \mathrm{m}$; bottom, after capsaicin injection, where clear examples of double-labeled neurons (arrowheads) and Fos-positive cells that are NK1

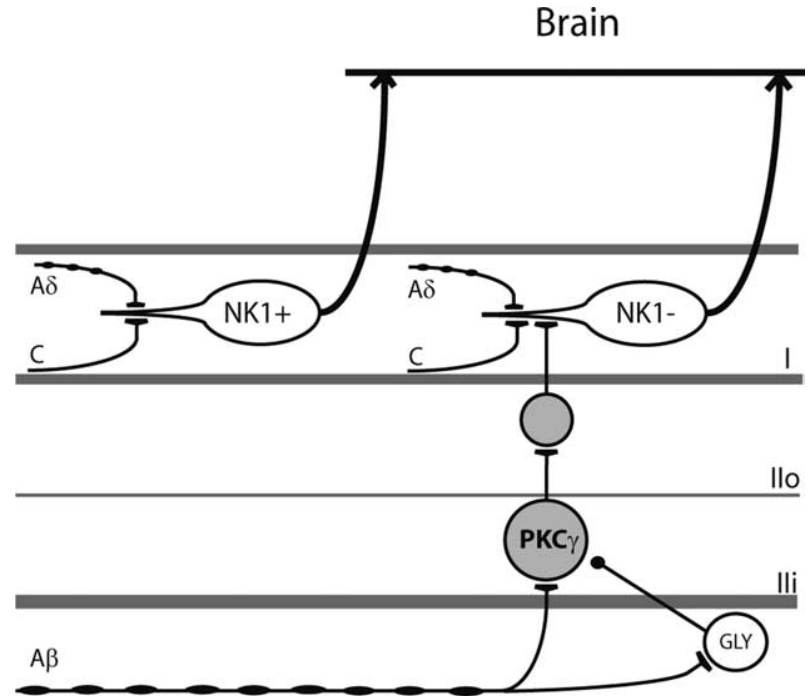

III-IV

excitatory interneuron

Figure 6. Schematic diagram illustrating the current understanding of the dorsal horn neural circuit involved in dynamic mechanical allodynia. PKC $\gamma$ neurons that receive innocuous input via myelinated afferent fibers are part of a local excitatory circuit that mediates dynamic mechanical allodynia after loss of glycinergic inhibitory control (Miraucourt et al., 2007). The exact location of the glycinergic interneurons (GLY) involved in the inhibitory control of the circuit is not known. Although the target of the PKC $\gamma$ interneurons is still a matter of investigation (Neumann et al., 2008), the current results provide evidence that the dorsal horn output neurons of the circuit are lamina I neurons that lack the NK1 receptor (NK1).

blocked spontaneous pain, thermal and mechanical hyperalgesia, cold and static allodynia but not dynamic allodynia (Gonzalez et al., 2000). Thus NK1 receptor antagonists may not be effective against $\mathrm{A} \beta$ fiber-signaled responses, and this would contribute to explain the lack of efficacy of NK1 receptor antagonists against painful neuropathies (Urban and Fox, 2000).

Using patch clamp in a spinal cord slice preparation from young rats, Torsney and MacDermott (2006) recently showed that disinhibition revealed monosynaptic and/or polysynaptic A fiber input onto lamina I and III NK1 receptor-expressing neurons and lamina I neurons that did not express NK1 receptors. Our work shows that, unlike noxious stimuli, light, dynamic mechanical stimuli applied under glycine-disinhibition induced Fos expression in neurons lacking the NK1 receptor. Torsney and MacDermott's findings could be linked to the use of spinal cord slices from young rats in which $\mathrm{A} \beta$ afferent terminals extend more dorsally than in the adult (Baccei and Fitzgerald, 2006). As such, the lack of a significant activation of NK1 receptor-bearing neurons in lamina III is consistent with the anatomical demonstration that NK1 receptor-expressing cells in lamina III receive only a limited innervation from $A \beta$ afferents (Todd, 2002). Moreover, Torsney and MacDermott (2006) used a mixture of

$\leftarrow$

receptor negative (arrows) are illustrated; scale bar, $20 \mu \mathrm{m}$. B, Bar histograms summarizing the percentages of NK1 receptor-expressing neurons and Fos-positive neurons that are doublelabeled in the different laminae of the MDH ( $n=3-4 /$ group). Fos expression was induced by light brushing of the ipsilateral lip after intracisternal strychnine or by capsaicin injection into the upper ipsilateral lip. Control animals (aCSF) received intracisternal aCSF and brushing without strychnine. I-Ilo, Laminae I and outer II; II-IIIo, laminae inner II and outer III; IIIi-IV, laminae inner III and IV; ${ }^{*} p<0.05$. 
bicuculline and strychnine to block both $\mathrm{GABA}_{\mathrm{A}}$ and glycine receptors, which implies that activation of different populations of dorsal horn neurons was revealed. In line with such idea, we found that blockade of $\mathrm{GABA}_{\mathrm{A}}$ or glycine receptors induced selective static or dynamic mechanical allodynia, respectively. Accordingly, in vivo electrophysiological studies have consistently demonstrated that bicuculline has no effect on low-threshold responses of dorsal horn neurons, but increases A $\delta$ fibermediated mechanical responses (Reeve et al., 1998; Kontinen et al., 2001; Seagrove et al., 2004). Finally, our results are also consistent with findings in a rat model of spinal nerve ligation in which selective chemical ablation of superficial dorsal horn neurons expressing the NK1 receptor did not alter electrophysiological response of dorsal horn neurons to brushing of the skin (Suzuki et al., 2005).

In summary, glycine disinhibition provides a selective, morphine-resistant and clinically relevant model for dynamic mechanical allodynia. It revealed that PKC $\gamma$ neurons which receive innocuous input via myelinated afferent fibers are part of a local excitatory circuit that mediates allodynia (Miraucourt et al., 2007). By showing that the circuit output goes through lamina I neurons that lack the NK1 receptor, the current results give a novel perspective on the mechanisms through which injury produces mechanical hypersensitivity.

\section{References}

Ahmadi S, Lippross S, Neuhuber WL, Zeilhofer HU (2002) PGE(2) selectively blocks inhibitory glycinergic neurotransmission onto rat superficial dorsal horn neurons. Nat Neurosci 5:34-40.

Allen BJ, Li J, Menning PM, Rogers SD, Ghilardi J, Mantyh PW, Simone DA (1999) Primary afferent fibers that contribute to increased substance P receptor internalization in the spinal cord after injury. J Neurophysiol 81:1379-1390.

Baccei M, Fitzgerald M (2006) Development of pain pathways and mechanisms. In: Wall and Melzack's textbook of pain (McMahon SB, Koltzenburg M, eds), pp 143-158. Oxford: Churchill Livingstone.

Baron R (2006) Mechanisms of disease: neuropathic pain-a clinical perspective. Nat Clin Pract Neurol 2:95-106.

Besse D, Lombard MC, Zajac JM, Roques BP, Besson JM (1990) Pre- and postsynaptic distribution of mu, delta and kappa opioid receptors in the superficial layers of the cervical dorsal horn of the rat spinal cord. Brain Res 521:15-22.

Beyer C, Roberts LA, Komisaruk BR (1985) Hyperalgesia induced by altered glycinergic activity at the spinal cord. Life Sci 37:875-882.

Bian D, Nichols ML, Ossipov MH, Lai J, Porreca F (1995) Characterization of the antiallodynic efficacy of morphine in a model of neuropathic pain in rats. Neuroreport 6:1981-1984.

Brown JL, Liu H, Maggio JE, Vigna SR, Mantyh PW, Basbaum AI (1995) Morphological characterization of substance P receptor-immunoreactive neurons in the rat spinal cord and trigeminal nucleus caudalis. J Comp Neurol 356:327-344.

Campbell JN, Meyer RA (2006) Mechanisms of neuropathic pain. Neuron 52:77-92.

Campbell JN, Raja SN, Meyer RA, Mackinnon SE (1988) Myelinated afferents signal the hyperalgesia associated with nerve injury. Pain 32:89-94.

Castro-Lopes JM, Tavares I, Coimbra A (1993) GABA decreases in the spinal cord dorsal horn after peripheral neurectomy. Brain Res 620:287-291.

Catheline G, Le Guen S, Besson JM (2001) Intravenous morphine does not modify dorsal horn touch-evoked allodynia in the mononeuropathic rat: a Fos study. Pain 92:389-398.

Coste J, Voisin DL, Miraucourt LS, Dallel R, Luccarini P (2008) Dorsal horn NK1-expressing neurons control windup of downstream trigeminal nociceptive neurons. Pain 137:340-351.

Coull JA, Beggs S, Boudreau D, Boivin D, Tsuda M, Inoue K, Gravel C, Salter MW, De Koninck Y (2005) BDNF from microglia causes the shift in neuronal anion gradient underlying neuropathic pain. Nature 438:1017-1021.

Dallel R, Dualé C, Molat JL (1998) Morphine administered in the substantia gelatinosa of the spinal trigeminal nucleus caudalis inhibits nociceptive activities in the spinal trigeminal nucleus oralis. J Neurosci 18:3529-3536.

Devor M (2006) Response of nerves to injury in relation to neuropathic pain. In: Wall and Melzack's textbook of pain (McMahon SB, Koltzenburg M, eds), pp 905-927. Oxford: Churchill Livingstone.

Dickenson AH, Kieffer B (2006) Opiates: basic mechanisms. In: Wall and Melzack's textbook of pain (McMahon SB, Koltzenburg M, eds), pp 427442. Oxford: Churchill Livingstone.

Dickenson AH, Sullivan AF (1986) Electrophysiological studies on the effects of intrathecal morphine on nociceptive neurones in the rat dorsal horn. Pain 24:211-222.

Field MJ, McCleary S, Hughes J, Singh L (1999a) Gabapentin and pregabalin, but not morphine and amitriptyline, block both static and dynamic components of mechanical allodynia induced by streptozocin in the rat. Pain 80:391-398.

Field MJ, Bramwell S, Hughes J, Singh L (1999b) Detection of static and dynamic components of mechanical allodynia in rat models of neuropathic pain: are they signalled by distinct primary sensory neurones? Pain 83:303-311.

Game CJ, Lodge D (1975) The pharmacology of the inhibition of dorsal horn neurones by impulses in myelinated cutaneous afferents in the cat. Exp Brain Res 23:75-84.

Gonzalez MI, Field MJ, Hughes J, Singh L (2000) Evaluation of selective NK(1) receptor antagonist CI-1021 in animal models of inflammatory and neuropathic pain. J Pharmacol Exp Ther 294:444-450.

Harvey RJ, Depner UB, Wässle H, Ahmadi S, Heindl C, Reinold H, Smart TG, Harvey K, Schütz B, Abo-Salem OM, Zimmer A, Poisbeau P, Welzl H, Wolfer DP, Betz H, Zeilhofer HU, Müller U (2004) GlyR alpha3: an essential target for spinal PGE2-mediated inflammatory pain sensitization. Science 304:884-887.

Honore P, Menning PM, Rogers SD, Nichols ML, Basbaum AI, Besson JM, Mantyh PW (1999) Spinal substance P receptor expression and internalization in acute, short-term, and long-term inflammatory pain states. J Neurosci 19:7670-7678.

Hughes DI, Scott DT, Riddell JS, Todd AJ (2007) Upregulation of substance $\mathrm{P}$ in low-threshold myelinated afferents is not required for tactile allodynia in the chronic constriction injury and spinal nerve ligation models. J Neurosci 27:2035-2044.

Ji RR (2004) Mitogen-activated protein kinases as potential targets for pain killers. Curr Opin Investig Drugs 5:71-75.

Ji RR, Baba H, Brenner GJ, Woolf CJ (1999) Nociceptive-specific activation of ERK in spinal neurons contributes to pain hypersensitivity. Nat Neurosci 2:1114-1119.

Keller AF, Beggs S, Salter MW, De Koninck Y (2007) Transformation of the output of spinal lamina I neurons after nerve injury and microglia stimulation underlying neuropathic pain. Mol Pain 3:27.

Knabl J, Witschi R, Hösl K, Reinold H, Zeilhofer UB, Ahmadi S, Brockhaus J, Sergejeva M, Hess A, Brune K, Fritschy JM, Rudolph U, Möhler H, Zeilhofer HU (2008) Reversal of pathological pain through specific spinal GABAA receptor subtypes. Nature 451:330-334.

Kontinen VK, Stanfa LC, Basu A, Dickenson AH (2001) Electrophysiologic evidence for increased endogenous gabaergic but not glycinergic inhibitory tone in the rat spinal nerve ligation model of neuropathy. Anesthesiology 94:333-339.

Lamotte C, Pert CB, Snyder SH (1976) Opiate receptor binding in primate spinal cord: Distribution and changes after dorsal root section. Brain Res 112:407-412.

Le Bars D, Guilbaud G, Jurna I, Besson JM (1976) Differential effects of morphine on responses of dorsal horn lamina $\mathrm{V}$ type cells elicited by $\mathrm{A}$ and C fibre stimulation in the spinal cat. Brain Res 115:518-524.

Lee YW, Chaplan SR, Yaksh TL (1995) Systemic and supraspinal, but not spinal, opiates suppress allodynia in a rat neuropathic pain model. Neurosci Lett 199:111-114.

Liu Y, Obata K, Yamanaka H, Dai Y, Fukuoka T, Tokunaga A, Noguchi K (2004) Activation of extracellular signal-regulated protein kinase in dorsal horn neurons in the rat neuropathic intermittent claudication model. Pain 109:64-72.

Malan TP, Mata HP, Porreca F (2002) Spinal GABA(A) and GABA(B) receptor pharmacology in a rat model of neuropathic pain. Anesthesiology 96:1161-1167.

Malcangio M, Ramer MS, Jones MG, McMahon SB (2000) Abnormal sub- 
stance $\mathrm{P}$ release from the spinal cord following injury to primary sensory neurons. Eur J Neurosci 12:397-399.

Mantyh PW, DeMaster E, Malhotra A, Ghilardi JR, Rogers SD, Mantyh CR, Liu H, Basbaum AI, Vigna SR, Maggio JE (1995) Receptor endocytosis and dendrite reshaping in spinal neurons after somatosensory stimulation. Science 268:1629-1632.

Matsumoto M, Xie W, Ma L, Ueda H (2008) Pharmacological switch in Abeta-fiber stimulation-induced spinal transmission in mice with partial sciatic nerve injury. Mol Pain 4:25.

Miraucourt LS, Dallel R, Voisin DL (2007) Glycine inhibitory dysfunction turns touch into pain through PKCgamma interneurons. PLoS ONE 2:e1116.

Moore KA, Kohno T, Karchewski LA, Scholz J, Baba H, Woolf CJ (2002) Partial peripheral nerve injury promotes a selective loss of GABAergic inhibition in the superficial dorsal horn of the spinal cord. J Neurosci 22:6724-6731.

Neumann S, Braz JM, Skinner K, Llewellyn-Smith IJ, Basbaum AI (2008) Innocuous, not noxious, input activates $\mathrm{PKC} \gamma$ interneurons of the spinal dorsal horn via myelinated afferent fibers. J Neurosci 28:7936-7944.

Noguchi K, Kawai Y, Fukuoka T, Senba E, Miki K (1995) Substance P induced by peripheral nerve injury in primary afferent sensory neurons and its effect on dorsal column nucleus neurons. J Neurosci 15:7633-7643.

Nojima H, Simons CT, Cuellar JM, Carstens MI, Moore JA, Carstens E (2003) Opioid modulation of scratching and spinal c-fos expression evoked by intradermal serotonin. J Neurosci 23:10784-10790.

Noma N, Tsuboi Y, Kondo M, Matsumoto M, Sessle BJ, Kitagawa J, Saito K, Iwata K (2008) Organization of pERK-immunoreactive cells in trigeminal spinal nucleus caudalis and upper cervical cord following capsaicin injection into oral and craniofacial regions in rats. J Comp Neurol 507:1428-1440.

Nozaki K, Moskowitz MA, Boccalini P (1992) CP-93,129, sumatriptan, dihydroergotamine block c-fos expression within rat trigeminal nucleus caudalis caused by chemical stimulation of the meninges. Br J Pharmacol 106:409-415

Ochoa JL, Yarnitsky D (1993) Mechanical hyperalgesias in neuropathic pain patients: Dynamic and static subtypes. Ann Neurol 33:465-472.

Paxinos G, Watson C (1997) The rat brain in stereotaxic coordinates. New York: Academic.

Presley RW, Menétrey D, Levine JD, Basbaum AI (1990) Systemic morphine suppresses noxious stimulus-evoked Fos protein-like immunoreactivity in the rat spinal cord. J Neurosci 10:323-335.

Reeve AJ, Dickenson AH, Kerr NC (1998) Spinal effects of bicuculline: Modulation of an allodynia-like state by an Al-receptor agonist, morphine, and an NMDA-receptor antagonist. J Neurophysiol 79:1494-1507.

Ren K (1999) An improved method for assessing mechanical allodynia in the rat. Physiol Behav 67:711-716.

Roberts LA, Beyer C, Komisaruk BR (1986) Nociceptive responses to altered GABAergic activity at the spinal cord. Life Sci 39:1667-1674.

Ruscheweyh R, Forsthuber L, Schoffnegger D, Sandkühler J (2007) Modification of classical neurochemical markers in identified primary afferent neurons with Abeta-, Adelta-, and C-fibers after chronic constriction injury in mice. J Comp Neurol 502:325-336.

Scholz J, Woolf CJ (2002) Can we conquer pain? Nat Neurosci 5 Suppl:1062-1067.

Seagrove LC, Suzuki R, Dickenson AH (2004) Electrophysiological charac- terisations of rat lamina I dorsal horn neurones and the involvement of excitatory amino acid receptors. Pain 108:76-87.

Sherman SE, Loomis CW (1994) Morphine insensitive allodynia is produced by intrathecal strychnine in the lightly anesthetized rat. Pain 56:17-29.

Sorkin LS, Puig S (1996) Neuronal model of tactile allodynia produced by spinal strychnine: effects of excitatory amino acid receptor antagonists and a mu-opiate receptor agonist. Pain 68:283-292.

Suzuki R, Rahman W, Rygh LJ, Webber M, Hunt SP, Dickenson AH (2005) Spinal-supraspinal serotonergic circuits regulating neuropathic pain and its treatment with gabapentin. Pain 117:292-303.

Todd AJ (2002) Anatomy of primary afferents and projection neurones in the rat spinal dorsal horn with particular emphasis on substance $P$ and the neurokinin 1 receptor. Exp Physiol 87:245-249.

Todd AJ, Koerber HR (2006) Neuroanatomical substrate of spinal nociception. In: Wall and Melzack's textbook of pain (McMahon SB, Koltzenburg M, eds), pp 73-90. Oxford: Churchill Livingstone.

Torebjörk HE, Vallbo AB, Ochoa JL (1987) Intraneural microstimulation in man. Its relation to specificity of tactile sensations. Brain 110:1509-1529.

Torsney C, MacDermott AB (2006) Disinhibition opens the gate to pathological pain signaling in superficial neurokinin 1 receptor-expressing neurons in rat spinal cord. J Neurosci 26:1833-1843.

Urban LA, Fox AJ (2000) NK1 receptor antagonists-are they really without effect in the pain clinic? Trends Pharmacol Sci 21:462-464; author reply 465

Vanegas H, Schaible HG (2004) Descending control of persistent pain: inhibitory or facilitatory? Brain Res Brain Res Rev 46:295-309.

Voisin DL, Guy N, Chalus M, Dallel R (2005) Nociceptive stimulation activates locus coeruleus neurones projecting to the somatosensory thalamus in the rat. J Physiol 566:929-937.

Vos BP, Strassman AM, Maciewicz RJ (1994) Behavioral evidence of trigeminal neuropathic pain following chronic constriction injury to the rat's infraorbital nerve. J Neurosci 14:2708-2723.

Wiesenfeld-Hallin Z, Aldskogius H, Grant G, Hao JX, Hökfelt T, Xu X] (1997) Central inhibitory dysfunctions: mechanisms and clinical implications. Behav Brain Sci 20:420-425; discussion 435-513.

Woolf CJ (1987) Central terminations of cutaneous mechanoreceptive afferents in the rat lumbar spinal cord. J Comp Neurol 261:105-119.

Woolf CJ (2004) Pain: moving from symptom control toward mechanismspecific pharmacologic management. Ann Intern Med 140:441-451.

Woolf CJ, Salter MW (2006) Plasticity and pain: role of the dorsal horn. In: Wall and Melzack's textbook of pain (McMahon SB, Koltzenburg M, eds), pp 91-105. Oxford: Churchill Livingstone.

Yaksh TL (1989) Behavioral and autonomic correlates of the tactile evoked allodynia produced by spinal glycine inhibition: effects of modulatory receptor systems and excitatory amino acid antagonists. Pain 37:111-123.

Yamamura H, Malick A, Chamberlin NL, Burstein R (1999) Cardiovascular and neuronal responses to head stimulation reflect central sensitization and cutaneous allodynia in a rat model of migraine. J Neurophysiol 81:479-493.

Zeilhofer HU, Zeilhofer UB (2008) Spinal dis-inhibition in inflammatory pain. Neurosci Lett 437:170-174.

Zhuang ZY, Gerner P, Woolf CJ, Ji RR (2005) ERK is sequentially activated in neurons, microglia, and astrocytes by spinal nerve ligation and contributes to mechanical allodynia in this neuropathic pain model. Pain 114: $149-159$. 